\title{
The Relationship of Shooting Skill with Functional Movement Performance and Attention Level of Basketball Players
}

\author{
Umut Canlı ${ }^{1}$, Çalık Veli Koçak ${ }^{2}$ \\ ${ }^{1}$ School of Physical Education and Sports, Tekirdag Namik Kemal University, Tekirdag, Turkey \\ ${ }^{2}$ Faculty of Sports Science, Hitit University, Corum, Turkey \\ Correspondence: Umut Canl1, School of Physical Education and Sports, Tekirdag Namik Kemal University, Tekirdag, \\ 59000, Turkey.
}

Received: December 18, 2018

doi:10.11114/jets.v6i12a.3926
Accepted: December 28, 2018 Online Published: January 1, 2019

URL: https://doi.org/10.11114/jets.v6i12a.3926

\begin{abstract}
The purpose of this study was to determine the relationship of shooting skill with the functional performances and attention levels of professional basketball players. Sixteen male basketball players (age $=20.6 \pm 2.30$ ) from university basketball team who were trained on regular basis participated in this study as volunteers. Participants' body height and body weight were measured and body mass indexes were calculated. D2 test of attention was utilized to determine the focus levels. Shooting skills were determined by shooting tests. Spearman Correlation Analysis was utilized to determine the correlation of shooting skill with functional movement performances and attention levels of participants. There was a moderate level of negative correlation $(r h o=-0.57 ; \mathrm{p}<0.05)$ between the shooting skill scores and deep squat scores which is one of the functional movement performances. A moderate level of positive correlation (rho = 0.54; $\mathrm{p}<0.05$ ) between TN-E (Total number of items processed-Total error score) scores and shooting skill scores were determined. Consequently, as the deep squat values of professional basketball players increases, the shooting skill decreases and with the increasing attention level, shooting skill increases.
\end{abstract}

Keywords: attention, basketball players, functional movement performance, shooting skill

\section{Introduction}

Basketball is characterized by intensive body contact, frequent intermittent running and jumping, demanding one-on-one situations, quick direction changes in combination with challenging technique, and coordination aspects like catching, throwing, passing, and dribbling (Arendt and Dick, 2015; Piasecki, Spindler, Warren, Andrish and Parker, 2013). One of the two main purposes of basketball is to make a good shot to score and the other one is to take necessary precautions against the opponent who is trying to score by shooting (Krause, Meyer and Meyer, 2008). Among all the physical skills utilized in game, most difficult to develop and also most important one is the shooting ability (Wissel, 2011). Besides, shooting is the most important determining factor that affects the outcome, the score, getting the win and achieving superiority (Malone, Gervais and Steadward, 2002). Coskun (2016) states that strength and durability of the muscle groups that help you to make well-balanced and accurate shot, affect the quality and success percentage of shoots positively. Wooten (2013) claims that a part of hitting the target in basketball is related with the confidence of the player, while the other part can be achieved by specially designed shooting training. It is believed that unpredictable factors such as importance of the game, attitude of the coach, opponent's defensive ability and mental state of the player affect the players shooting performance, as well as the predictable factors like competition atmosphere, intensity of noise, light and scene behind the basket (Isik and Gencer, 2007; Bayraktar and Kurtoglu, 2009) .

It is thought that in addition to all these features, the Functional Movement Screen (FMS) parameters may also be related to the shooting performance. The FMS was designed to identify functional movement deficits and asymmetries that may be predictive of general musculoskeletal conditions and injuries, with an ultimate goal of being able to modify the identified movement deficits through individualized exercise prescription (Cook, Burton, \& Hoogenboom, 2016). Also, athlete's mobility and stability, muscular strength and flexibility, coordination and balance levels could be evaluated with FMS test battery (Cook, Burton, Kiesel, Bryant and Torine, 2010; Yildiz, Pınar and Gelen, 2017).

One of the issues discussed in the study is the relation between attention level and shooting performance. Attention is a necessary element for an effective sportive performance, to filter perceived information, to balance different perceptions, 
to control the thought processes which includes adding emotional precautions to perceived information, and to concentrate to a certain task (Tunc, 2013). Attention level changes in athletes and children depending on the motivation, environmental factors and areas of interest (Kumartasli and Bastug, 2010). Athlete's loss of performance after the drop in concentration due to distraction proves the importance of selective attention and constant distribution of attention (Abernethy, 1993). Distribution of attention to more than one focus points during activity emerges as one of the most important factors affecting the performance (Maggil, 2004). Attention is one of the most important elements that athletes need for success (Kartal, Dereceli, and Kartal, 2016).

This study is important in aspects of determining the factors affecting the shooting performances of basketball players, and it is also important for the development and design of different training programs that will help to improve the shooting ability. Thus, the aim of the study; is to indicate the correlation of shooting skill with functional movement performances and attention levels of basketball players.

\section{Method}

\subsection{Subjects}

Sixteen basketball players $($ age $=20.6 \pm 2.30$; body height $=188.3 \pm 7.64$; body weight $=83.2 \pm 12.56$; bmi $=23.2 \pm$ 2.14) who regularly trained volunteered to the study. All participants were in university team in the mid of season, injury-free and passed the federative medical examination. One-on-one interviews with each player were conducted by the main researcher, who was legally responsible for explaining the experimental procedures and observing any apparent physical or psychological diseases. Then, all participants signed the freely-given and informed consent form according to the Declaration of Helsinki. All players were familiarized with the experimental procedures and the requirements of the physical and technical tests.

\subsection{Measurements and Tests}

\subsubsection{Anthropometric Measurements}

The body height measurements were taken when the participants were barefeet, their body weights were evenly distributed to both feet, the heels were joined together and were in contact with the stadiometer, the head was positioned in the Frankfort plane, the shoulders were relaxed with the arms by sides. Participants' body weights were measured using electronic platform scales, as barefeet and with only shorts, t-shirts on (Ozer, 2009). Body mass index was calculated according to BMI $\left(\mathrm{kg} / \mathrm{m}^{2}\right)=$ body weight $(\mathrm{kg}) /(\text { body height })^{2}(\mathrm{~m})$.

\subsubsection{Functional Movement Screen}

The FMS is a comprehensive screen intended to measure fundamental movement patterns (Frost, Beach, Callaghan and McGill, 2012), according to seven fundamental movement patterns: the deep squat, hurdle step, in-line lunge, shoulder mobility, active straight leg raise, trunk stability push-up, and rotary stability and three clearing examinations. Three repetitions of each screen were completed, and the best performed repetition was recorded for further analysis (Cook, Burton, Hoogenboom and Voight, 2014). The patterns were evaluated on a scale of 3, 2, 1 and 0, represented according to the relevant criteria: 3-performs the movement correctly without any compensation, complying with standard movement expectations associated with each test; 2 -able to complete the movement but must compensate in some way to perform the fundamental movement; 1-unable to complete the movement pattern or is unable to assume the position to perform the movement; 0-pain anywhere in the body (Cook et al., 2014). Approximately $10 \mathrm{~s}$ of rest were provided between trials, and $1 \mathrm{~min}$ between tests. Subjects returned to the starting position between each attempt. After the seven scored patterns, the athlete could achieve a maximum of 21 points. Except for the deep squat and trunk stability push-up, each side of the body was assessed unilaterally. An FMS specialist with three years of experience conducted the tests.

\subsubsection{Basketball Shooting Test}

Two point shooting without fatigue protocol each player, in one of three series, performs two jump shots from five different positions, ten shots in total. Player's starting position is on the right wing; at position number I. Shooting positions are set at distance of five meters from the vertical projection of the hoop's center on the floor. There is no time limit for the shots. Two other players catch the ball and pass it back to the player. There is a three-minute rest period between each shooting series. Total score was determined by calculating successful shots in each series (Pojskic, Separovic, and Uzicanin, 2011).

\subsubsection{D2 Test of Attention}

The $\mathrm{d} 2$ Test of Attention, which measures selective attention depending on time, was developed by Brickenkamp and Rump (2016). The $\mathrm{d} 2$ test measures quality of discrimination performance of similar stimuli, processing speed and rule compliance, allowing the estimation of individual attention and concentration performance. There are 14 lines and 47 characters on a test which can be applied both individually and in groups. Characters consist of letters 'p' and 'd' with at 
least one and at most four marks at the top and bottom. The test taker is expected to mark the right character, namely the 'd' letter with two dashes at the top and bottom, within the specified time $(20 \mathrm{sec}$. for each line) (Brickenkamp and Zillmer, 1998). Caglar and Koruc (2016) purposed to determine the reliability and validity d2 Test of Attention for Turkish athlete. ANOVA for repeated measures showed significant differences between different test intervals $(\mathrm{p}<0.05)$. This finding indicated that there was practice effect in the $\mathrm{d} 2$ Test scores. As a reliability coefficient intraclass correlation coefficient was estimated for four test administrations. The highest intraclass correlation coefficient obtained from data was $\mathrm{R}=0.86$ for $\mathrm{TN}$ (Total Number processed) and the lowest coefficient was $\mathrm{R}=0.69$ for $\mathrm{CP}$ (Concentration Performance) $(n=58)$. Internal consistency coefficients were also calculated $(n=701)$. It was found that Cronbach alfa coefficients ranged from 0.93 to 0.96 and Spearman Brown internal consistency coefficients (split-half method) were between 0.91 to 0.96 . As a result, the obtained results on reliability and validity of $\mathrm{d} 2$ Test of Attention show that this test can be used to evaluate selective and sustained attention in Turkish athletes for practical and research purposes.

\subsection{Procedures}

All participants were evaluated according to anthropometrics, FMS, test of attention and shooting performance. The evaluation took place on two different days. First day, between 10:00 a.m. and 13:00 p.m, they took part in the laboratory portion, the evaluation of anthropometrics and FMS; after 5:00 p.m., in a large class and quiet environment, the test of attention were performed.in group. At the beginning and before the FMS assessment, each subject's age, body height, body weight and body mass index were measured and recorded. Next day, between 10:00 a.m. and 12:30 p.m., shooting performance test was performed. Before starting the test, the participants were practiced a warm-up protocol involving 10 minutes of general warm-up, 7 minutes of dynamic stretching and 12 minutes of special shooting drills.

\subsection{Statistical Analyses}

Descriptive statistics (mean, standard deviation (Sd), minimum, maximum variables) were calculated for each parameter. Spearman Correlation Analysis was used to determine the relationship between shooting performance and FMS and attention variables. All statistical analysis was computed using the Statistics Package for Social Sciences (version 22.0; IBM Corporation, New York, NY, USA).

\section{Results}

Table 1 indicates the descriptive statistics of basketball players for age, anthropometric features and functional movement screen test. Table 2 indicates descriptive statistics of basketball players' attention levels and shooting skill scores. Table 3 indicates a moderate level of negative correlation between squat values and shooting skills of basketball players ( $r=-0.57 ; \mathrm{p}<0.05)$. There was no relationship between in-line lunge, shoulder mobility, active straight leg raise, trunk push-up, rotary stability, FMS total score and shooting skill scores of basketball players ( $>0.05)$. A moderate level of positive correlation between TN-E scores and shooting skill scores was determined $(r=0.54 ; p<0.05)$. But, there was no relationship between concentration scores and shooting skill scores ( $p>0.05)$.

Table 1. Descriptive statistics of age, anthropometric and functional movements of basketball players

\begin{tabular}{lcccc}
\hline Variables & Mean & Sd & Minimum & Maximum \\
\hline Age $(\mathrm{y})$ & 20.6 & 2.30 & 19.0 & 27.1 \\
Height $(\mathrm{cm})$ & 188.3 & 7.64 & 178.0 & 205.0 \\
Weight $(\mathrm{kg})$ & 83.2 & 12.56 & 68.0 & 107.0 \\
Body mass index $\left(\mathrm{kg} / \mathrm{m}^{2}\right)$ & 23.3 & 2.14 & 20.9 & 28.2 \\
Deep squat & 2.1 & 0.40 & 2.0 & 3.0 \\
Hurdle step & 2.4 & 0.49 & 2.0 & 3.0 \\
In-line lunge & 2.5 & 0.44 & 2.0 & 3.0 \\
Shoulder mobility & 2.9 & 0.27 & 2.0 & 3.0 \\
Active straight leg raise & 2.8 & 0.35 & 2.0 & 3.0 \\
Trunk push- up & 2.1 & 0.61 & 1.0 & 3.0 \\
Rotary stability & 2.00 & 0.00 & 2.0 & 2.0 \\
FMS total score & 17.0 & 1.49 & 14.5 & 20.0 \\
\hline
\end{tabular}

$\mathrm{y}=$ year; $\mathrm{cm}=$ centimeters; $\mathrm{kg}=$ kilograms; $\mathrm{km} / \mathrm{m} 2=$ kilometers/ square meter; FMS= functional movement screen. 
Table 2. Descriptive statistics of basketball players' attention levels and shooting skills

\begin{tabular}{lcccc}
\hline Variables & Mean & Sd & Minimum & Maximum \\
\hline TN-E & 354.1 & 141.94 & 44 & 581 \\
CP & 162.8 & 37.163 & 66 & 243 \\
Shooting skill (n) & 10.9 & 3.66 & 5 & 19 \\
\hline
\end{tabular}

$\mathrm{TN}-\mathrm{E}=$ Total number of items processed-Total error score (Total performance); $\mathrm{CP}=$ Concentration score; $\mathrm{n}=$ shooting score

Table 3. The relationship of FMS and attention values of basketball players' shooting skills

\begin{tabular}{lcccccccccc}
\hline Variables & d.squat & h.step & lun. & s.mob & a.s.l.r & p-up & st. & tfms & TN-E & CP \\
Shooting skill & $-0.57^{*}$ & 0.43 & -0.23 & -0.20 & -0.30 & -0.38 & - & -0.35 & $0.54^{*}$ & 0.44 \\
\hline
\end{tabular}

$\mathrm{p}<0.05^{*}$ d.squat $=$ deep squat; h.step= hurdle step; lun= in-line lunge; s.mob= shoulder mobility; a.s.l.r= active straight leg raise; $\mathrm{p}$-up= trunk push-up; st= rotary stability; $\mathrm{tfms}=$ total functional movement screen score; TN-E= Total number of items processed-Total error score (Total performance); $\mathrm{CP}=$ Concentration score

\section{Discussion}

The purpose of this study was to determine the level of relationship of functional movement performance and attention levels with the shooting skill. In the study, a moderate level of negative correlation was determined between deep squat values, which belongs to functional movement system, and shooting skill. No correlation has been found between shooting skill and other FMS parameters and total FMS scores. Full deep squatting is not often required in modern daily life, general exercise and sport moves (https://www.functionalmovement.com). In the basketball shot dynamics are as follows; feet are shoulder width, knees are slightly bent, the body lunges forward and center of gravity is around the hips (Kuru and Savas, 2008). Hence, while taking the shot, you do not squat down as deep as in deep squat position and this may be one of the reasons that explain the negative correlation between the shooting skill and deep squat. No studies found in the literature that examines the relationship between functional movement performances and technical skills of basketball players. But on different disciplines, there is a lot of studies where the relationship between functional movement screen scores and functional performance of athletes are investigated (Kiesel, Plisky and Voight, 2007; Chorba, Chorba, Bouillon, Overmyer and Landis, 2010; Okada, Huxel and Nesser, 2011; Parchmann and McBride, 2011).

A moderate level of positive correlation between TN-E score which measures the accuracy and speed of attention performance (Caglar and Koruc, 2016), and shooting scores. It is seen that focusing the attention on a proper stimulus and keeping the focus are an important factors for success in sports (Caglar and Koruc, 2016). In addition to having proficient technique and excellent physical conditioning, athletes still need a high level of attention and optimal arousal level to obtain successful performance. In precision sports such as archery, rifle shooting, and basketball free throw, attention has been considered as the most important psychological factor dominating performance during triggering or shooting (Hsieh, Huang and Hung, 2010). No studies found in the literature that investigated the relationship between shooting abilities and attention levels of basketball players. But on different disciplines, there are studies where the relationship between attention level and performance of athletes are investigated. Experimental results showed that elite archers increased both attention and meditation during the shooting process (Lee, 2009). Their attention and meditation levels reached the highest value at the moment of release. Many archers did not realize their attention level was decreased by the short 'thought' of other things except shooting (Manoilov, 2016).

Concentration means focusing all the attention in one point (Tudos, Predoiu and Predoiu, 2015) and no relationship between concentration scores and shooting scores. However, concentration is important for every individual because it enables the individuals to utilize their internal resources and potential at the best level. Only a fully focused mind shows maximum performance (Erdogdu, 2015). Attention level changes in athletes and children depending on the motivation, environmental factors and areas of interest (Kumartasli and Bastug, 2010). In a study conducted on 10 successful and 10 unsuccessful shots of elite basketball players, a meaningful difference was observed between the players who made a great shot and ones that were not successful as much. This difference is associated with looking longer at the target before taking the shot. In the early stages of aiming a specific target, it is decided that a longer period of time is required to focus. At the shooting stage, it is found that aiming is distorted (Wilson, Vine and Wood, 2009).

\section{Conclusion}

The study found that higher the level of attention of basketball players, better the shooting performances get. Basketball coaches or trainers can make a contribution to shooting performances of their players by applying special shooting training in addition to that issue, they can also get support get from expert trainers and utilize the practices that are aiming to increase attention level. 


\section{References}

Abernethy, B. (1993). Attention. In R. N. Singer, M. Murphey, L. K. Tennant (Eds.), Handbook of research on sport psychology (pp. 127-170), New York: Macmillan Publishing Company.

Arendt, E., \& Dick, R. (2015). Knee injury patterns among men and women in collegiate basketball and soccer: NCAA data and review of literature. The American journal of sports medicine, 23(6), 694-701. https://doi.org/10.1177/036354659502300611

Bayraktar, B., \& Kurtoğlu, M. (2009). Performance in sport, effective factors, evaluation and enhancement. Clinical Development, 22(1), 16-24.

Brickenkamp, R., \& Rump, G. (2016). Die stabilitat des Aufmerksamkeits-Belastungs-Tests (Test d2) über langere Zeitabschnitte. Diagnostica, 12(1), 17-24.

Brickenkamp, R., \& Zillmer, E. (1998). The d2 test of attention. Seattle: Hogrefe \& Huber Publishers.

Caglar, E., \& Koruc, Z. (2016). Reliability and validity of d2 test of attention for athletes, Hacettepe Journal of Sport Sciences, 17(2), 58-80.

Chorba, R. S., Chorba, D. J., Bouillon, L. E., Overmyer, C. A., \& Landis, J. A. (2010). Use of a functional movement screening tool to determine injury risk in female collegiate athletes. North American journal of sports physical therapy: NAJSPT, 5(2), 47-54.

Cook, G., Burton, L., \& Hoogenboom, B. (2016). Pre-participation screening: the use of fundamental movements as an assessment of function-part 1. North American journal of sports physical therapy: NAJSPT, 1(2), 62-72.

Cook, G., Burton, L., Hoogenboom, B. J., \& Voight, M. (2014). Functional movement screening: the use of fundamental movements as an assessment of function-part 2. International journal of sports physical therapy, 9(4), 549-563.

Cook, G., Burton, L., Kiesel, K., Bryant, M., \& Torine, J. (2010). Movement: functional movement systems: screening, assessment, and corrective strategies (Vol. 24). Aptos, CA: On Target Publications.

Coskun, A. (2016). Shoot in basketball. Marmara University School of Physical Education and Sports, Department of Physical Education and Sports Teaching, Sports Sciences Seminar.

Erdogdu, F. (2015). The effect of using adaptive motivation strategies on student motivation and achievement. Doctoral Dissertation. Ankara University, Institute of Education Sciences, Ankara.

Frost, D. M., Beach, T. A., Callaghan, J. P., \& McGill, S. M. (2012). Using the Functional Movement Screen ${ }^{\text {TM }}$ to evaluate the effectiveness of training. The Journal of Strength \& Conditioning Research, 26(6), 1620-1630. https://doi.org/10.1519/JSC.0b013e318234ec59

Hsieh, T. C., Huang, C. J., \& Hung, T. M. (2010). Relationships between heart rate variability, attention, and athletic performance., 8(4), 473-475. https://doi.org/10.1080/1612197X.2010.9671964

Isik, T., \& Gencer, R. T. (2007). Technical analyze of team performance in basketball: evaluation of home and away field performances. Hacettepe Journal of Sport Sciences, 18(3), 101-108.

Kartal, R., Dereceli, C., \& Kartal, A. (2016). The analysis of the attention levels of 10-12 aged children playing fencing. Sport Overview, Journal of Sports and Educational Sciences, 3(2), 82-88.

Kiesel, K., Plisky, P. J., \& Voight, M. L. (2007). Can serious injury in professional football be predicted by a preseason functional movement screen? North American journal of sports physical therapy: NAJSPT, 2(3), 147.

Krause, J., Meyer, D., \& Meyer, J. (2008). Basketball skills and drills. Champaign, IL: Human Kinetics.

Kumartasli, M., \& Bastug, G. (2010). Examination of attention levels of athletes who do Taekwondo, Karate and Muaythai. Ovidius University Annals, Series Physical Education \& Sport/Science, Movement \& Health, 10(2).

Kuru, C., \& Savas, S. (2008). Basic basketball. Ankara: Ata Publishing.

Lee, K. (2009). Evaluation of attention and relaxation levels of archers in shooting process using brain wave signal analysis algorithms. Sci Sensitivity, 12(3), 341-350.

Magill, R. A. (2004). Motor learning and control: concepts and applications (7th ed.). Boston: McGraw Hill.

Malone, L. A., Gervais, P. L., \& Steadward, R. D. (2002). Shooting mechanics related to player classification and free throw success in wheelchair basketball. Journal of Rehabilitation Research and Development, 39(6), 701-710.

Manoilov, P. (2016). EEG power spectrum analysis during mental task performance. In Proceedings of International 
Conference on Computer Systems and Technologies.

Okada, T., Huxel, K. C., \& Nesser, T. W. (2011). Relationship between core stability, functional movement, and performance. The Journal of Strength \& Conditioning Research, 25(1), 252-261. https://doi.org/10.1519/JSC.0b013e3181b22b3e

Ozer, M. K. (2009). Kinantropometry, morphological planning in sports (2nd ed.). Ankara: Nobel Publishig.

Parchmann, C. J., \& McBride, J. M. (2011). Relationship between functional movement screen and athletic performance. The Journal of Strength \& Conditioning Research, 25(12), 3378-3384. https://doi.org/10.1519/JSC.0b013e318238e916

Piasecki, D. P., Spindler, K. P., Warren, T. A., Andrish, J. T., \& Parker, R. D. (2013). Intraarticular injuries associated with anterior cruciate ligament tear: findings at ligament reconstruction in high school and recreational athletes: an analysis of sex-based differences. The American journal of sports medicine, 31(4), 601-605. https://doi.org/10.1177/03635465030310042101

Pojskic, H., Separovic, V., \& Uzicanin, E. (2011). Reliability and factorial validity of basketball shooting accuracy tests. Sport Scientific and Practical Aspects, 8(1), 25-32.

Tudos, S., Predoiu, A., \& Predoiu, R. (2015). Topographical memory and the concentration of attention in top female tennis players. Procedia-Social and Behavioral Sciences, 190, 293-298. https://doi.org/10.1016/j.sbspro.2015.05.001

Tunc, A. (2013). The analysis of the attention levels of children playing golf. Master's Thesis. Selcuk University, Health Sciences Institute, Konya.

Wilson, M. R., Vine, S. J., \& Wood, G. (2009). The influence of anxiety on visual attentional control in basketball free throw shooting. Journal of Sport and Exercise Psychology, 31(2), 152-168. https://doi.org/10.1123/jsep.31.2.152

Wissel, H. (2011). Basketball: step to success (3th ed.). Champaign, IL: Human Kinetics.

Wootten, M. (2013). Coaching basketball successfully (2nd ed.). Champaign, IL: Human Kinetics.

Yıldız, S., Pınar, S., \& Gelen, E. (2017). Functional training for child tennis players. LAP Lambert Academic Publishing.

\section{Copyrights}

Copyright for this article is retained by the author(s), with first publication rights granted to the journal.

This is an open-access article distributed under the terms and conditions of the Creative Commons Attribution license which permits unrestricted use, distribution, and reproduction in any medium, provided the original work is properly cited. 